\title{
Foregrounding Daily Data Collection on Archaeological Fieldwork
}

\author{
Artur Petrosyan, Hayk Azizbekyan, Boris Gasparyan, Roberto Dan, \\ Arsen Bobokhyan, and Mariam Amiryan
}

\section{OVERVIEW}

\begin{abstract}
Daily data collection during archaeological fieldwork forms the basis for later interpretation and analysis. Across the world, we observe a wide variety of digital data collection methods and tools employed during fieldwork. Here, we detail the daily practices at four recent survey and excavation projects in the South Caucasian country of Armenia. As archaeology continues to become ever more digital, it is useful to consider these day-to-day recording processes at a typical field project. We provide details on both the types of data collected and the ways they are collected so as to foreground these topics. Finally, we reflect on how our work is currently impacted by digital changes and how it may continue to change in the future.
\end{abstract}

Keywords: Armenia, archaeology, daily data collection, digital methods, excavation, survey, lab analysis, data recording systems, Kotayk province, Vayots Dzor province, 3D modeling, georeferenced data, GIS, drones, databases

This review outlines the day-to-day activities of data collection at four typical archaeological excavations and surveys. Every day, throughout the world, we archaeologists undertake field research. This requires recording what we do-for example, how we excavate, where our finds are located, what we find, and how we analyze what we observe. Recording data about fieldwork has been central to archaeology since it began as an academic discipline founded on scientific methods in the nineteenth century. It forms the basis for our subsequent analyses, reports, publications, and public outreach and education about the human past. However, what we record and the mundane processes of recording it often receive less attention (outside specialist circles) than our processes of examining and interpreting the past, which we find more engaging. Yet, the data we record today and how we record them not only form the center of our own analyses but also serve as the foundation for all future research and knowledge creation. Consequently, we intend to shine a light on the actual, typical type of field recording and data collection that occurs today around the world. We hope that this serves as a type of snapshot of what most archaeologists are doing on a daily basis, which can both encourage all of us to reflect on our own practices and inform practical planning for digital workflows in the coming years.

We emphasize the practical implementations of data recording because we recognize a divergence in existing archaeological publications on digital methods. Although many digital archaeology publications may focus on the latest gadgets and software, these experiments are entangled with the privilege that often comes from generous research budgets (a few examples in this journal: Casana et al. 2017; Cobb et al. 2019; Lindsay and Kong 2020). Experimentation diverts time and relies on specialized skill sets. These advances, therefore, may not represent what is actually happening on the ground at any given moment, although we expect these technologies will see wider adoption over time based on increasing accessibility. The following overview of data collection during fieldwork aims to foreground daily practice in the minds of all readers as well as digital specialists. We try to anticipate the questions a digital specialist would ask when joining a field project in order to design structures for the data from that project.

\section{ARCHAEOLOGY IN ARMENIA}

Our four field projects are located in the country of Armenia in the Armenian Highlands, in an important interface zone between the Ancient Near East and the Eurasian Steppe-the border between Europe and Asia, even today. Armenia has a long history of archaeological fieldwork that has produced a deep archive of records and data (Lindsay and Smith 2006). This historical context sets the stage for the description of how we practice archaeology today.

Advances in Archaeological Practice 9(4), 2021, pp. 402-414

Copyright (C) The Author(s), 2021. Published by Cambridge University Press on behalf of Society for American Archaeology DOI: 10.1017/aap.2021.30 


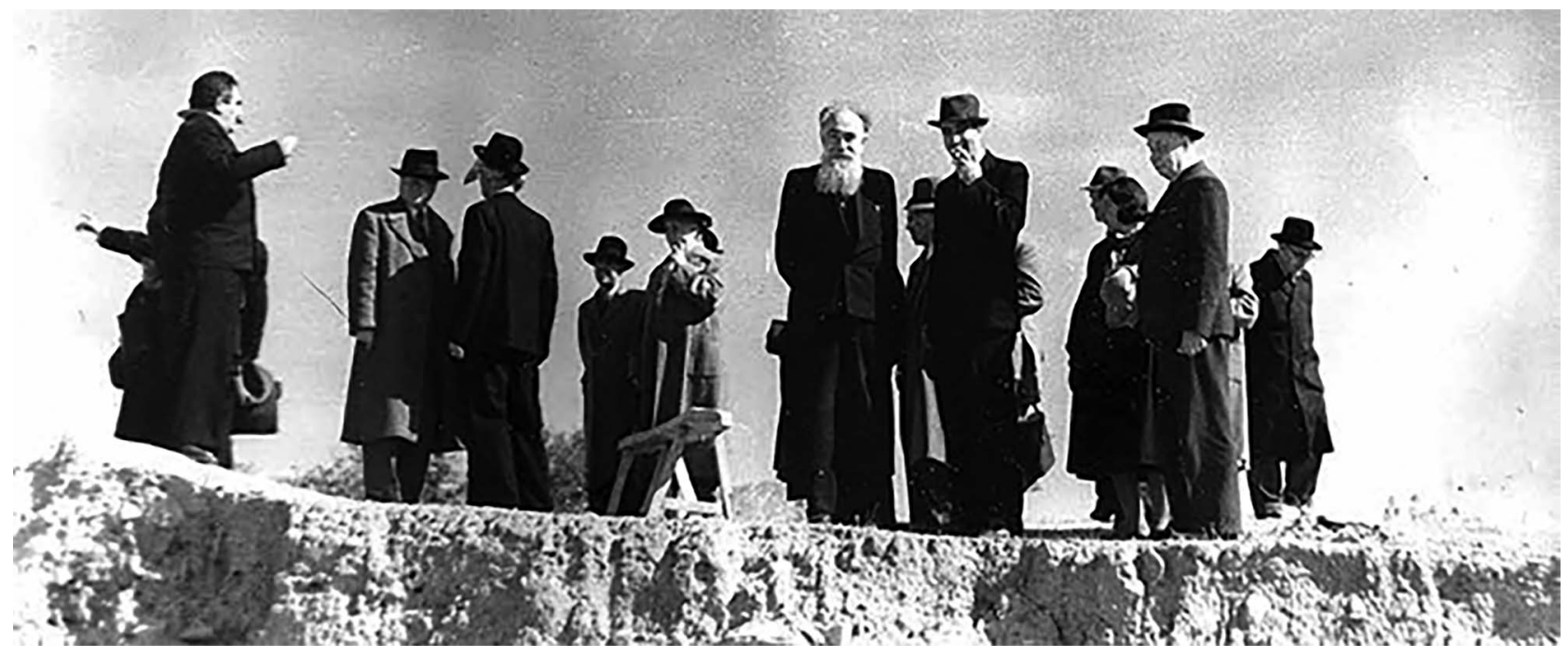

FIGURE 1. Academic guests at the Dvin site, headed by Hovsep Orbeli (in the middle), 1950. (Photo archive of the Dvin Museum, photo 54, provided by A. Zhamkochyan and N. Hakobyan.)

Archaeological excavations in Armenia began in the second half of the nineteenth century with work at the site of Ani, under the direction of Nikolai Marr and Joseph Orbeli. Archaeological investigations then increased significantly during the Soviet period starting in the 1920s and 1930s at well-known sites such as Shengavit, Vagharshapat, Armavir, Amberd, Dvin, and locations in the Lake Sevan basin and elsewhere (Avetisyan and Bobokhyan 2012:7)

Archaeological research gained steam after World War II and into the decades that followed, greatly facilitated by the establishment of the Institute of Archaeology and Ethnography in 1959 (Figure 1). This institute has achieved significant results in the investigation of anthropogenesis-the processes of the formation of early agricultural societies - and the study of the history and culture of ancient and medieval Armenia, which are a result of a long period of large-scale investigations. In the post-Soviet period from 1990 on, more than 250 excavations have been undertaken in Armenia.

\section{EXAMPLE FIELD PROJECTS 1 AND 2: THE KOTAYK SURVEY PROJECT AND VAYOTS DZOR SURVEY PROJECT}

We now turn to contemporary field projects in Armenia to provide a description of the daily recording and data collection processes at each project. We provide a detailed account of what happens in terms of data collection about surface survey, excavation, and the processing of artifacts.

\section{Survey}

Kotayk and Vayots Dzor are the names of two provinces located in central Armenia, west and south of Lake Sevan, respectively (Figure 2). The goal of the two related Kotayk and Vayots Dzor archaeological surveys is to map out archaeological remains from all time periods located in these provinces. At a total of over 4,000 $\mathrm{km}^{2}$, various methods are deployed to maximize research coverage while minimizing time input. Initial work combines remote sensing with extensive car-based survey to document both known and new sites. Our project uses orthorectified LANDSAT images and digital topographic maps $(1: 10,000)$ to examine environmental, topographic, and taphonomic data that can identify potential archaeological features. After recording these in our geographic information system (GIS), we combine ground-truthing of these potential sites with an exploratory car-survey to visually locate new sites on the ground (Figure 3). We visit each site to identify individual pieces of evidence such as pottery and other artifacts that can provide a preliminary site date. The most visible larger-scale features are documented with drone-based aerial photography for the creation of 3D models and orthophotos that can be used to produce plans of selected sites. Our projects have also been recognized with a 2019 Europa Nostra Award / European Heritage Award in the research category for our experimentation with predictive modeling in GIS to identify new sites.

Based on these extensive efforts, the next step is to undertake intensive survey of selected sites. We aim for complete sampling within our identified borders of each site using parallel transect fieldwalking. The location of each site is recorded with a handheld GPS device, and then all the artifacts are collected and documented in specific Microsoft Access databases. The surface pattern of ceramics, combined with topography and architectural plans, supports our research on the chronology and different forms of occupation and activity at each site.

We face several challenges during field investigations related to environmental and weather conditions. Wind and rain inhibit drone activity, whereas high vegetation can limit visibility for locating surface materials. These issues increase the time required for documenting individual sites and lead to differential sampling coverage among sites. Additionally, prior 


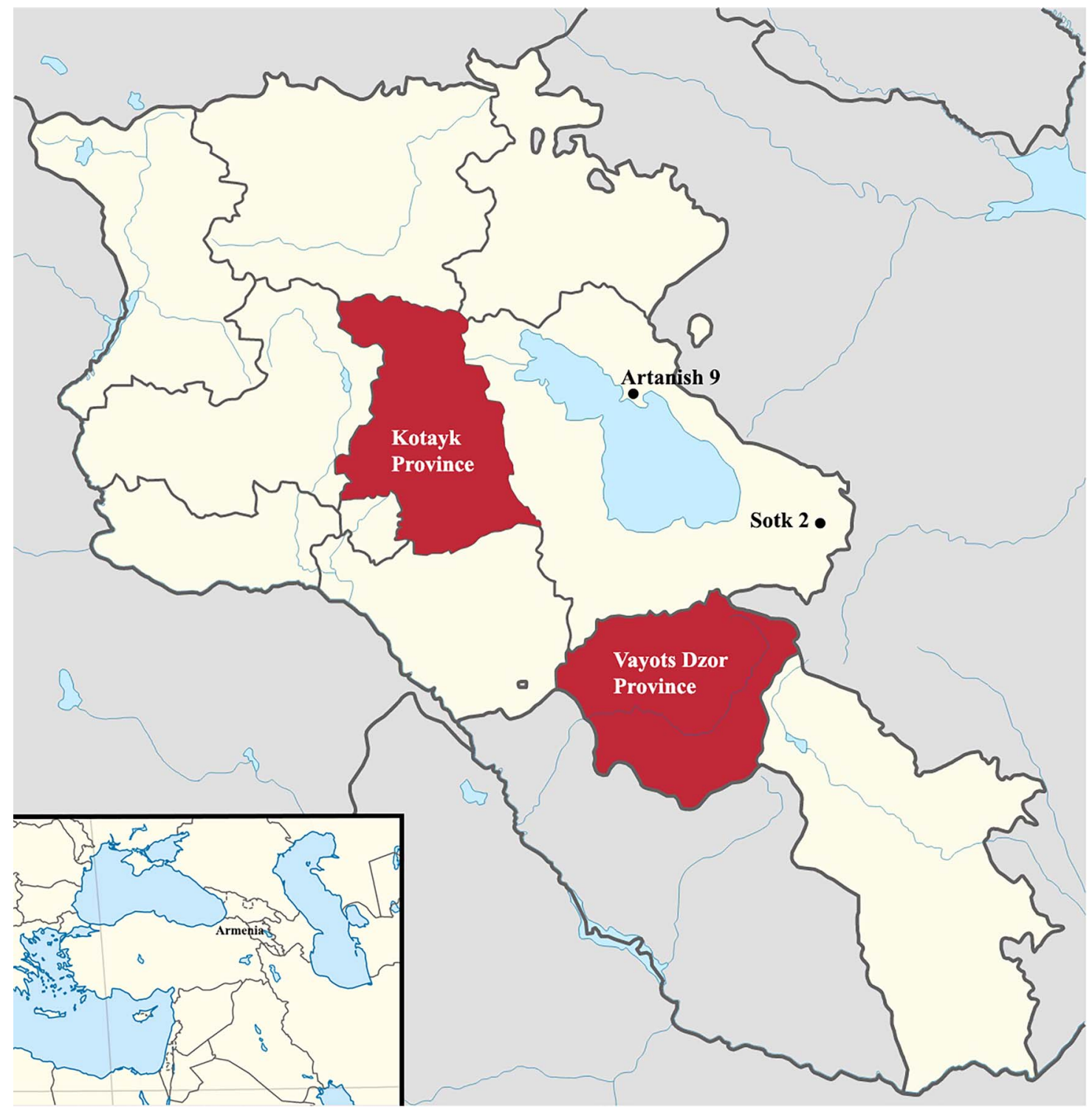

FIGURE 2. Map showing the locations of archaeological projects mentioned in this text. (Maps from Wikipedia.)

archaeological investigation, alluvial deposits, looting, and other topographical modifications can also impact sampling results. For these reasons, our team collects all pottery seen on the surface, without applying any selection. The average amount of pottery collected from a site could be around 25 to 50 fragments.

\section{Excavation}

In tandem with the field survey, we select sites for either a small test excavation $(1 \times 1 \mathrm{~m}$ trench) or a more extensive excavation. We apply a flexible approach to our stratigraphic excavation methods that adapts to local orographic and morphological circumstances and optimizes the time and financial resources to address particular research questions.
We systematically document each phase of excavation in a primary excavation diary for the entire site as well as a second diary that records an individual trench. On individual paper cards, we record details about the description of each stratigraphic unit and context (Figure 4).

The location of many objects is georeferenced using the total station. Professional digital cameras provide photographic documentation of the excavation, and drones provide frequent aerial views that can also be used for the creation of 3D models. These models contain orthophotos and elevations that document structures and contexts.

Initial processing of artifacts takes place in a lab house near the excavations and involves cleaning, drawing/description, and 


\section{DIGITAL REVIEW}

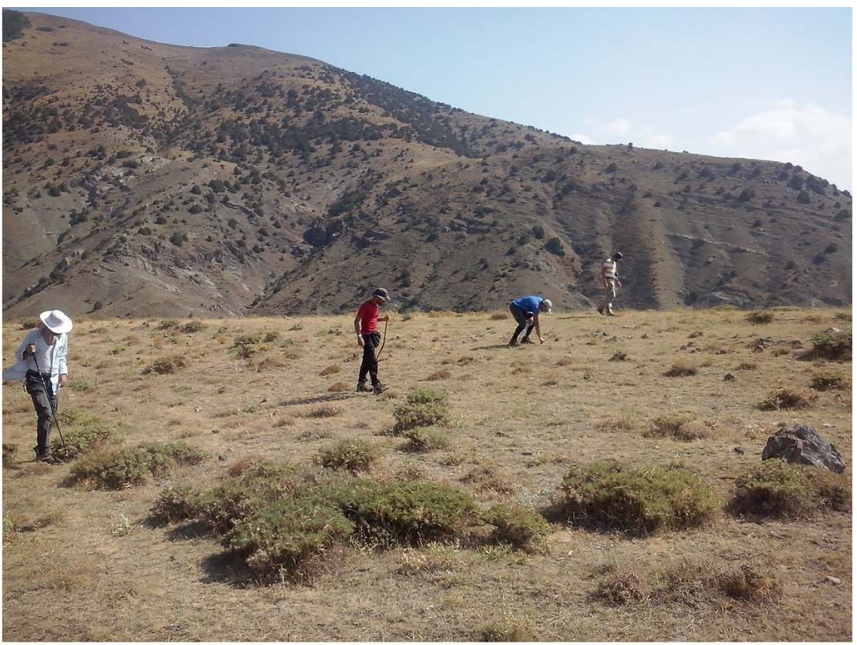

Collected Material

Comments on current site condition

Coordinates: $\mathrm{N}$
Altitude

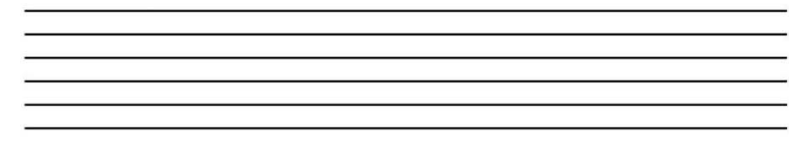

Notes (map, site size etc.)
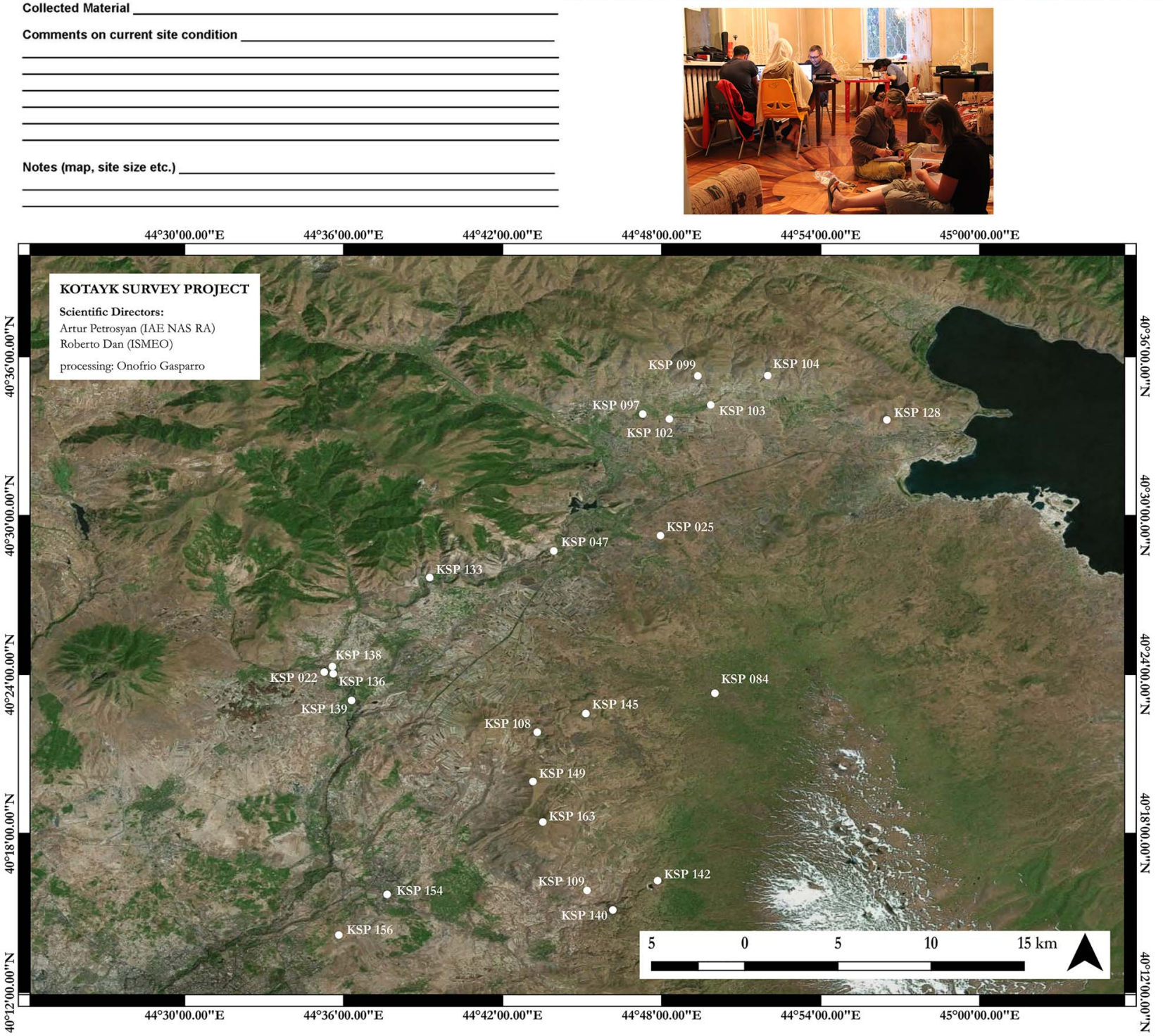

FIGURE 3. The survey form used during the Kotayk and Vayots Dzor projects, together with photographs of the survey team field-walking and processing artifacts in the lab house in Kaghsi. Below is the map of sites documented in 2019 in Kotayk Province. (Photo Archive of Kotayk Survey Project.) 
DIGITAL REVIEW

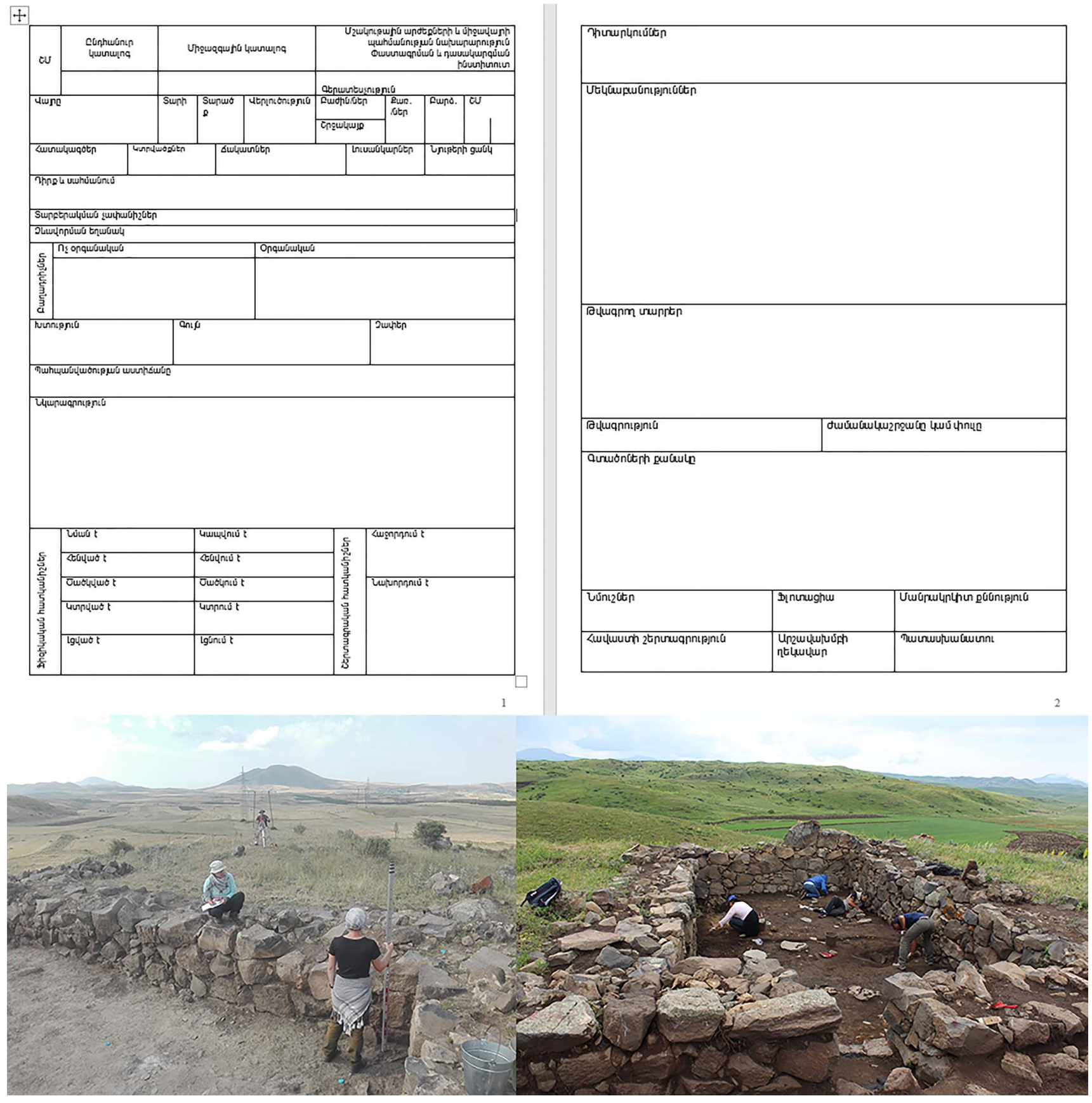

FIGURE 4. Stratigraphic Unit Cards used during the archaeological excavations of the Kotayk and Vayots Dzor Survey Projects cataloging identifiers and location/year (top left), context characteristics (middle left), stratigraphic relationships (bottom left), free-form description and comments (top right), dating, finds, and team members (bottom right). Photographs of data recording in Room-4 (left) and excavations of Urartian and post-Urartian layers in Room-1 (right), both in Building A of the Solak-1 site. (Photo Archive of Kotayk Survey Project.)

basic restoration. From there, the materials travel to the Institute of Archaeology and Ethnography in the capital city of Yerevan for conservation and curation. At each site, visible architectural remains are subject to minor maintenance and consolidation intervention, in preparation for future public presentation. Specialists analyze each category of material collected from each site.

\section{EXAMPLE FIELD PROJECTS 3 AND 4: SOTK 2 AND ARTANISH 9}

The Institute of Archaeology and Ethnography began the Ushkiani research project in 2010 to investigate the shores of Lake Sevan in the Gegharkunik Province. The investigation started with a surface 


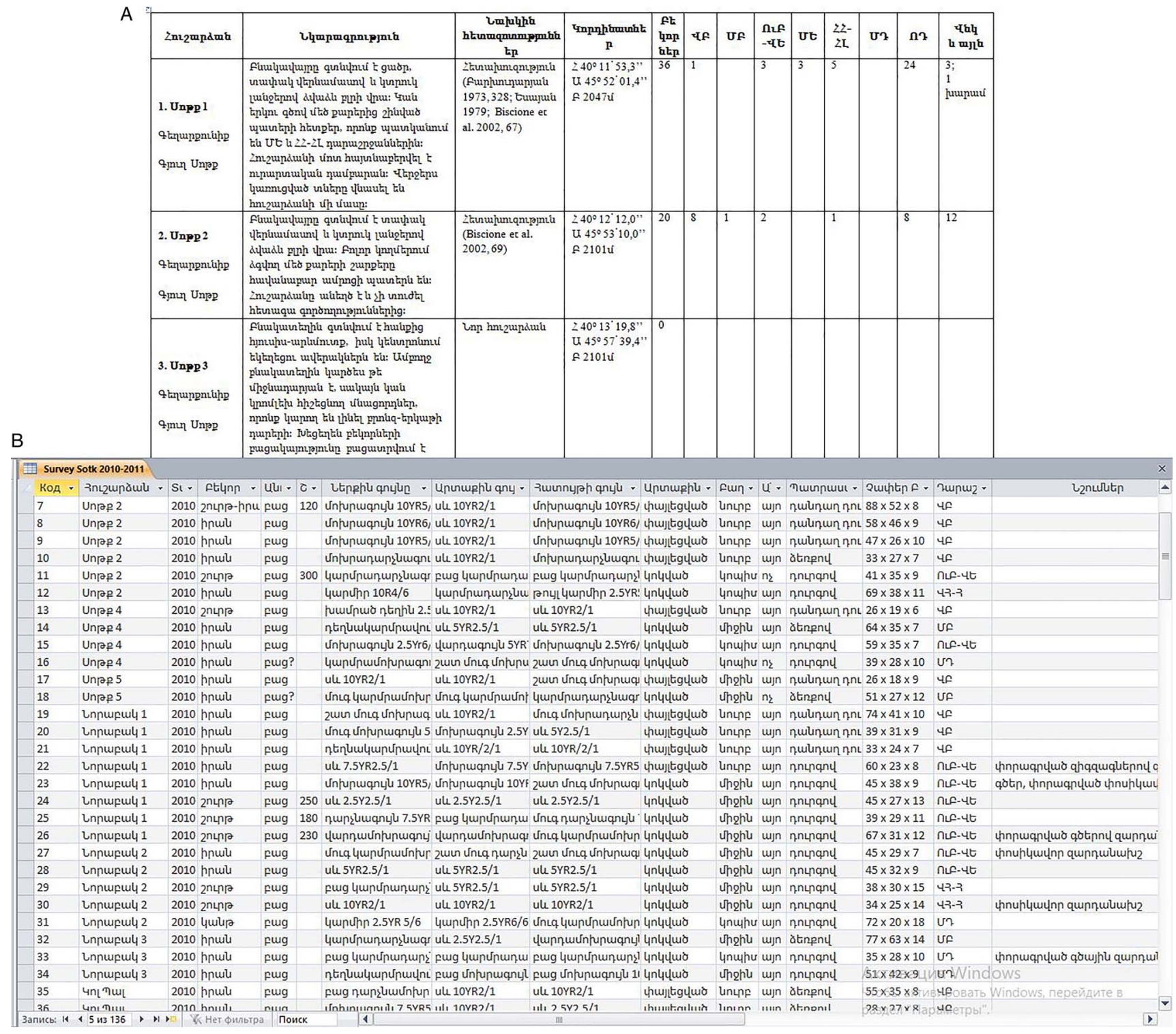

FIGURE 5. (A) First few of a list of sites documented by the Ushkiani project that records name, description, bibliography, coordinates, sherd and obsidian quantities, and age; (B) part of a database of objects found on the surface of those sites that records the number and name of the site, year of discovery, and some descriptive information about the objects such as surface color, measurements, and age.

survey that mapped dozens of sites. Surface materials (such as sherds and obsidian) from each site were recorded in a database (Figure 5). Among the sites, two were identified for intensive excavation: Sotk 2 and Artanish 9

\section{Excavation of Sotk 2}

The fortified settlement Sotk 2 is located in the village of Sotk, southeast of Lake Sevan, and it was first identified by an Armenian-Italian expedition in the late 1990s. The site holds a very strategic position on the road leading to an eponymous gold mine and to the Sotk Pass, which connects the southern and eastern Caucasus. Excavations in 2011-2015 revealed that the settlement was occupied from the Early Bronze Age (with some interruptions) until the ninth to eighth centuries BC. Archaeological, archaeobiological, and archaeometallurgical data paint a picture of an ancient society engaged in agriculture and animal husbandry, as well as in metal and obsidian production, which was likely connected to the still-active local mines.

Our team laid out a variety of trench sizes-usually $5 \times 5 \mathrm{~m}$ or $5 \times 8 \mathrm{~m}$-across the site to address various research questions. After undertaking geophysical exploration, multiple trenches were opened to enable parallel excavations, which were to be 


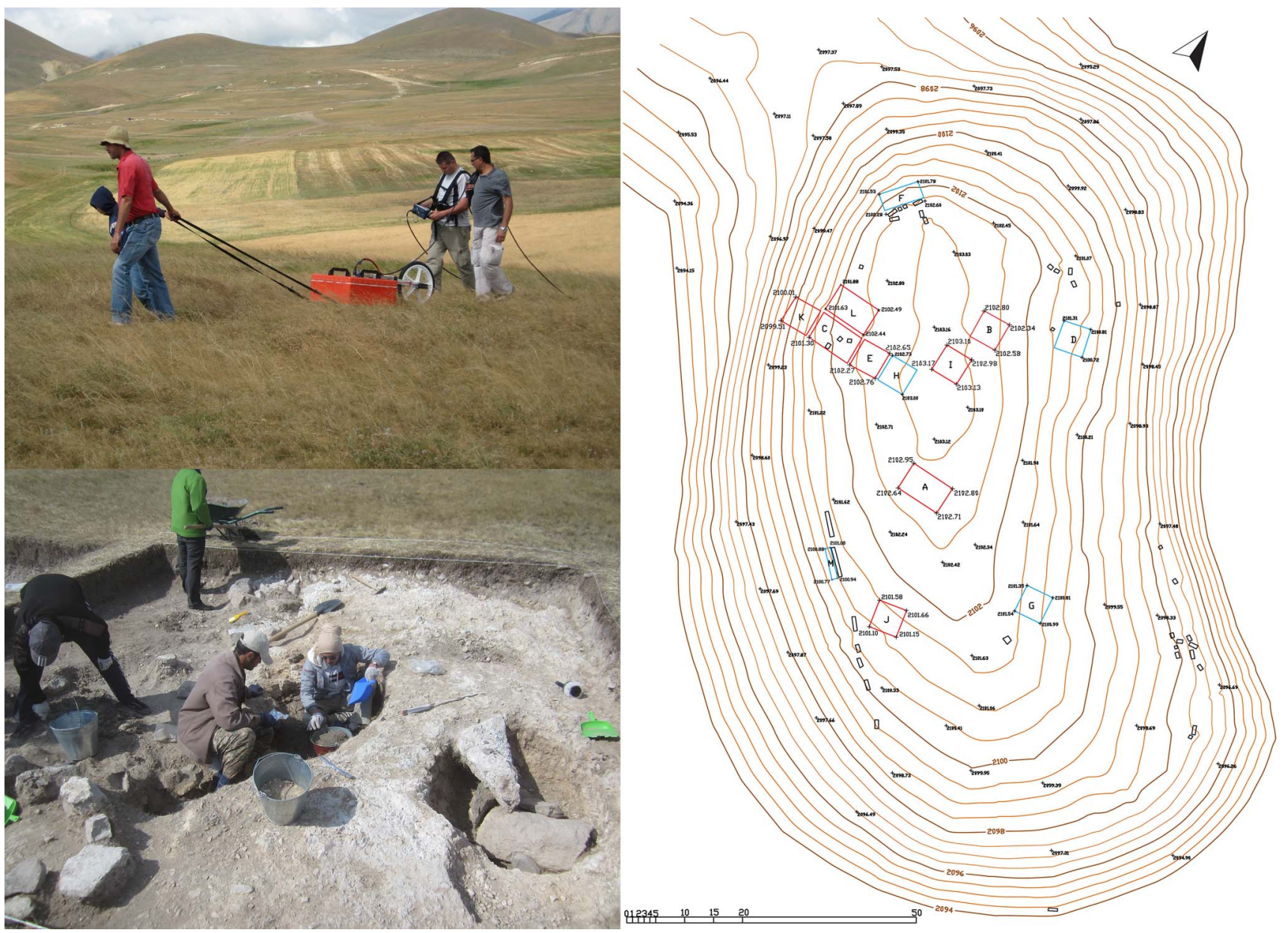

FIGURE 6. Geophysical research at the Sotk 2 site (2011) and fieldwork at the Sotk 2 site (Trench H, 2013). Topographic map of the Sotk 2 site indicating locations of trenches (2011-2015). (Photo Archive of Ushkiani Research Project.)

completed during one period of approximately 30 working days (Figure 6). All spatial data regarding each excavation were recorded at 1:20 scale on drawing paper. Every working day, the artifacts and situational and architectural units (including stones that were not part of any structure) in the trench were translated into a drawing with the appropriate coordinates and depths. For the depths, the highest of the trench corners was selected as the zero point from which all measurements were made with lines. Later, the drawings were digitized, which made it possible to work with them as needed (Figure 7). At the end of each excavation season, the newly excavated rectangles were added to the topographic map of the site (Figure 6).

Each separate artifact or group of artifacts was given a "passport" label in the field with the relevant information (Figure 8). At the end of each working day, the site was photographed to record all new situations. Because pottery sherds were the most abundant materials obtained from the excavations of the settlement, they were cleaned and registered at the end of each day. At the end of the excavations, all artifacts were registered on the spot and the statistics were created (Figure 9). After excavations, the finds were cleaned and conserved accordingly in the laboratory. Afterward, they were photographed, drawn, and studied separately. Based on the information obtained from the findings, a digital database of Sotk 2 was created, which includes the data of the passport label and descriptive details of each find (Figure 10). Table 1 displays the general schema for the Sotk 2 database, indicating the types of information collected about all objects.

\section{Excavation of Artanish 9}

The settlement Artanish 9 is located between the Artanish and Shoghakat (formerly Shorzha) communities of Gegharkunik Province, northeast of Lake Sevan. Excavations in 2020 and 2021 revealed that this is an Early Bronze Age settlement. Until 2015, the site was unknown in professional circles, and it was discovered by the Ushikani expedition. This site is still unique as an Early Bronze Age settlement because no archaeological excavations have ever taken place in this region.

The excavation technique of Artanish 9 is almost identical to that of Sotk 2. The section of the hill on which the settlement is 

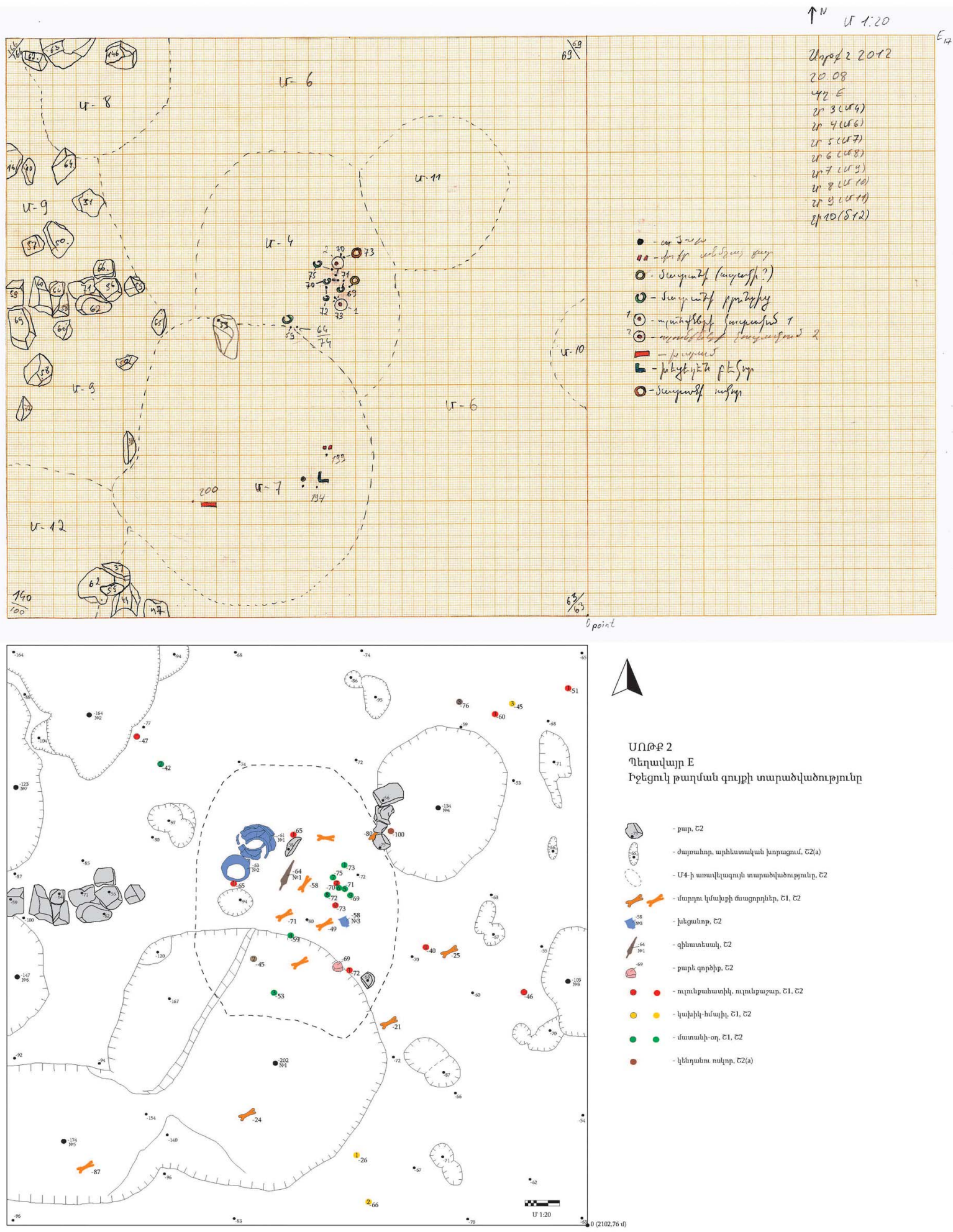

FIGURE 7. (top) The hand-drawn plan of one day showing units outlined with dashes and labeled with large numbers, points recording depths, and the prior-day depths written in the corners; the right column records units, layers, and the symbols for the found objects at the Sotk 2 site, Trench E (August 20, 2012); (bottom) the digitization and restoration of Late Bronze Age intramural burials based on the daily drawings. (Photo Archive of Ushkiani Research Project.) 


\begin{tabular}{|c|c|c|}
\hline \multicolumn{3}{|c|}{ Epmutiln2 9, 2021} \\
\hline ¿и́umph! & - & \\
\hline Ttinuılujn & - & \\
\hline Uhuılnn & - & \\
\hline Ghpm & & \\
\hline GnpnpL̆um & - & \\
\hline Eunz̄nnıวјnı & - & \\
\hline Ejll & - & \\
\hline
\end{tabular}

\begin{tabular}{|c|c|c|}
\hline \multicolumn{3}{|c|}{ Upunuí12 9, 2021} \\
\hline 【น์umphџ & - & 15.08 \\
\hline 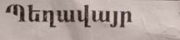 & - & $A / \bar{n}$ \\
\hline Оhuццnр & - & 25 \\
\hline Gtpun & & 1 \\
\hline 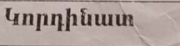 & - & $350 \times 120$ \\
\hline 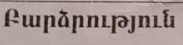 & - & 90 \\
\hline $\mathrm{UJl}_{\mathrm{Jl}}$ & - & oquefu \\
\hline
\end{tabular}

FIGURE 8. The format for a "passport" paper label, used to record in-field information about an object, group of objects, or a sample. Information collected includes date, trench, unit, layer, coordinates, depth, and notes. This example to the right is for a hearth, Artanish 9 site (2021).

situated is replete with traces of masonry. Consequently, after initially choosing the most obvious masonry according to its dimensions, an excavation trench of $4 \times 3 \mathrm{~m}$ was set up. Then, the excavation was expanded according to the situation. Field documentation was carried out mainly as at Sotk 2 . Here, aerial photographs were taken alongside each extension of the excavation, with the drone flown about twice a week (Figure 11). The final drawings of the excavation were obtained with the help of these photographs. Afterward, the data of these and daily situational plans were compared (Figure 12).

\section{OBSERVATIONS}

We hope that by describing these typical recording and data collection processes, we can encourage conversations on digital field recording. For example, what are the challenges faced by a typical field project in terms of day-to-day recording needs? How are these currently being met by digital workflows, and what do we hope will occur in the future? In what places can digital tools help increase efficiency and accuracy?

Our first observation is that data are collected at multiple discrete scales. At the highest level, sites are identified in the landscape through a variety of methods. Next, we study the spatial layout of each site itself with a focus on its architectural features. Finally, we record the location of individual artifacts on each site and then we subject those artifacts to specialized off-site analyses. We must, therefore, also consider the logistics of transporting and tracking each of these individual objects after their removal from the site. Each of these scales of data collection requires different methods for recording and digitizing information, and different types of information are recorded for each (Kansa and Kansa 2021). Table 2

\section{Statistics}

\section{Trench H (2013)}

\begin{tabular}{|c|c|c|c|c|c|c|c|}
\hline $\begin{array}{l}\text { Uưum- } \\
\text { phly }\end{array}$ & $\begin{array}{c}\text { Uhurynp/ } \\
\text { Ctpun }\end{array}$ & $\begin{array}{c}\text { Cunhuminip } \\
\text { putgtnteq }\end{array}$ & પ્f & $\begin{array}{l}\text { Uf- } \\
\text { nLF }\end{array}$ & પ๕ưu. & Фnpp qunudntukp & し2nưfutp \\
\hline 13.08 & $0 / 0$ & 50 & 4 & 20 & 20 & 1 ựnplpph ptulunn & \\
\hline 14.08. & $1 / 1$ & 44 & 3 & 15 & 14 & 1 gnimuqumn futgktaftilnn & \\
\hline 15.08. & $1 / 1$ & 225 & 20 & 55 & 39 & - & \\
\hline \multirow{3}{*}{16.08} & $1 / 1$ & 48 & 2 & 15 & 6 & - & \\
\hline & $2 / 1$ & 25 & 1 & 11 & 4 & - & \\
\hline & $3 / 1$ & 12 & 1 & 5 & 6 & - & \\
\hline \multirow{3}{*}{17.08} & $1 / 1$ & 20 & 1 & 15 & 7 & - & \\
\hline & $2 / 1$ & 5 & - & 1 & 3 & - & \\
\hline & $3 / 1$ & 53 & - & 32 & 7 & 1 gnifumqumn, futigtapthunn & \\
\hline \multirow{4}{*}{18.08} & $1 / 1$ & 1 & - & 1 & - & - & \\
\hline & $2 / 1$ & 6 & - & 3 & - & - & \\
\hline & $3 / 1$ & 7 & - & 3 & 2 & - & \\
\hline & $4 / 1$ & 1 & - & 1 & - & - & \\
\hline \multirow{5}{*}{21.08} & $1 / 1$ & 21 & 2 & 2 & 3 & - & \\
\hline & $2 / 1$ & 11 & - & 4 & 3 & - & \\
\hline & $3 / 1$ & 13 & - & 10 & 7 & - & \\
\hline & $4 / 1$ & 7 & - & 7 & 2 & - & \\
\hline & $5 / 1$ & 8 & - & 5 & - & - & \\
\hline 22.08 & $1 / 1$ & 16 & 2 & 4 & 8 & - & \\
\hline
\end{tabular}

FIGURE 9. A table of statistics recorded in the field about objects found in Trench H at the Sotk 2 site (2013). Data recorded include date, unit, layer, sherds, obsidian, small finds, age, and notes. 

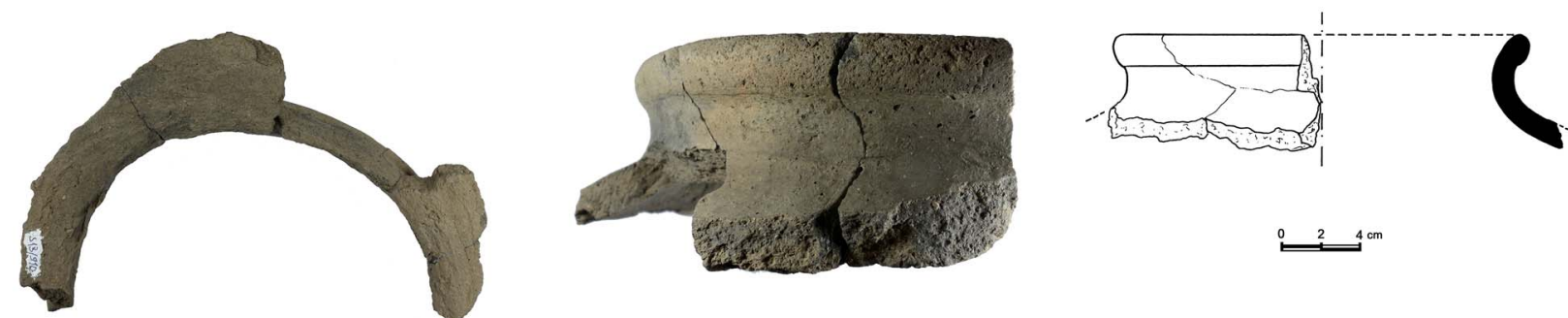

\begin{tabular}{|c|c|c|c|c|c|c|c|c|c|c|c|c|c|}
\hline Bce объекты Access $\odot$ « & \multicolumn{12}{|c|}{ 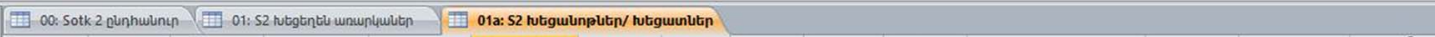 } & \multirow{2}{*}{ 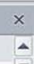 } \\
\hline \begin{tabular}{|l|l|l|l|l} 
Houck. & 0 \\
\end{tabular} & Oplul - Ftlynge - & 2lumueui . & 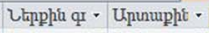 & Zuunnıjpl - Upunü • & funt - & Uuqun . & - Tuunpi - & 2urutip . & 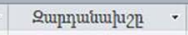 & - $\tau_{\text {nıppp/ }}$ & $\iota_{2}$ nufutan . & 0 & \\
\hline \multirow{25}{*}{ 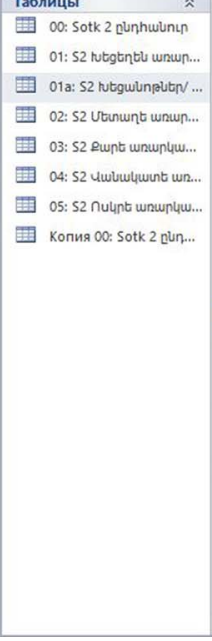 } & $4 \mathrm{rim}$ & closed & dark gray 7.5 dark gray 7. & dark gray 7.5 polished & fine & 曰 & hand & $35 \times 15 x$ & & 180 & & (i) $(0)$ & \\
\hline & $5 \mathrm{rm}$ & closed & gray 5 YR $5 /:$ reddish gray & reddish brow smoothed & coarse & $\square$ & slow whe & $42 \times 37 x$ & & 150 & +6 & $\theta(0)$ & \\
\hline & $6 \mathrm{rm}$ & closed & reddish gray brown $7.5 \mathrm{Yl}$ & dark gray 7.5 smoothed & coarse & $\square$ & slow whe & $30 \times 20 \times$ & horizontal lines and crc & c 100 & +5 & (1) (0) & \\
\hline & $7 \mathrm{rm}$ & closed & dark reddish dark reddish & black 7.5YR: polished & fine & $\square$ & hand & $56 \times 50 \times$ & relief belt omament un & a. 110 & & (1)(0) & \\
\hline & $8 \mathrm{rim}$ & closed & light reddish 1 pink $5 Y R 71$ & light reddish $t$ smoothed & medium & $\square$ & slow whe & $49 \times 35 x$ & & 130 & & (1)(0) & \\
\hline & $9 \mathrm{rm}$ & closed & pink 7.5 YR 7 dark gray 7. & dark gray 7.5 smoothed & medium & $\square$ & slow whe & $30 \times 26 x$ & & 90 & & $\theta(0)$ & \\
\hline & $10 \mathrm{rm}$ & closed & brown $7.5 Y$ Y reddish gray & brown 7.5YR polished & fine & 曰 & slow whe & $23 \times 21 x$ & & 90 & & (1)(0) & \\
\hline & 11 body & - & gray $2.5 \mathrm{Y} 6 /$ black $10 \mathrm{YR}$ & black 7.5YR polished & medium & $\square$ & hand & $47 \times 35 \times$ & oblique parallel lines bc & & & (1)(0) & \\
\hline & $12 \mathrm{rm}$ & closed & pink 5 YR $8 / 4$ pink 5 YR $8 /$ & pink 5YR8/4 smoothed & medium & $\square$ & hand & $35 \times 34 x$ & & 130 & & (1)(0) & \\
\hline & $13 \mathrm{rm}$ & closed & reddish yello light reddish & red 2.5YR6/t smoothed & fine & $\square$ & hand & $47 \times 46 x$ & & 110 & & $0(0)$ & \\
\hline & $14 \mathrm{rm}$ & closed & gray 5 YR $5 / 1$ dark gray 2. & black 7.5YR' polished & fine & 曰 & slow whe & $60 \times 40 x$ & & & & (l) $(0)$ & \\
\hline & $15 \mathrm{rm}$ & closed & light gray 7.5 pink $7.5 \mathrm{YR} 7$ & light gray 7.5 smoothed & medium & $\square$ & hand & $21 \times 20 x$ & & & & $(10)$ & \\
\hline & $16 \mathrm{rm}$ & closed & pink 5 YR $7 / 2$ reddish yello & black 7.5 YR smoothed & medium & $\square$ & hand & $43 \times 34 x$ & crucible (for which spe & e 90 & & (1)(0) & \\
\hline & 17 base & - & very dark gr: black $10 \mathrm{YR}$ & black 7.5YR polished & fine & $\square$ & hand & $34 \times 31 x$ & & 40 & & (i) $(0)$ & \\
\hline & 18 base & - & dark reddish weak red 2 & dark reddish, smoothed & medium & $\square$ & hand & $59 \times 39 x$ & & 140 & & (l) $(0)$ & \\
\hline & $19 \mathrm{rim}$ & opened & weak red 2.5 dark reddish & reddish gray : polished & fine & 曰 & hand & $35 \times 27 x$ & & 80 & & (1)(0) & \\
\hline & $20 \mathrm{rm}$ & closed & light reddish 1 reddish gray & dark reddish smoothed & medium & $\square$ & hand & $42 \times 39 x$ & & 140 & & (1)(0) & \\
\hline & $21 \mathrm{rm}$ & closed & gray 5 YR $6 / 1$ black 7.5 YR & black 7.5YR 2 smoothed & medium & 曰 & hand & $55 \times 38 x$ & & & & $\theta(0)$ & \\
\hline & $22 \mathrm{rm}$, body. & closed & weak red 2.5 black $10 \mathrm{YR}$ & black 7.5YRZ polished & fine & घ & slow whe & $56 \times 40 x$ & & 180 & & (O) $(0)$ & \\
\hline & 23 base & - & pinkish gray ! black $10 \mathrm{YR}$ & black 7.5YR polished & fine & $\square$ & hand & $65 \times 54 x$ & & 40 & & (1)(0) & \\
\hline & $24 \mathrm{rim}$ & - & pink 5 YR $7 /<$ black 10YR & black 7.5YR_ polished & fine & $\square$ & hand & $56 \times 36 x$ & & 260 & btrpuhg lu ipu & (1)(0) & \\
\hline & 25 body & - & light gray 7.5 gray $7.5 Y R$ & light gray 7.5 polished & fine & 曰 & slow whe & $46 \times 28 x$ & incised two paralell ans & 60 & & (1)(0) & \\
\hline & $26 \mathrm{im}$ & opened & pinkish gray! dark gray 5$\}$ & reddish brow polished & medium & घ & slow whe & $41 \times 34 \mathrm{x}$ & & & Wh & (1)(0) & \\
\hline & 27 base & - & weak red 2.5 black $10 \mathrm{YR}$ & black 7.5YR polished & fine & 田 & slow whe & $38 \times 34 \mathrm{x}$ & ралоел" "Пар: & paverotit & & (5) $(0)$ & - \\
\hline & Запись: : 4 † 16 из 1381 & $1, n$ & \begin{tabular}{l|l} 
₹ Без фильтра & Поиск
\end{tabular} & $|4|$ & & IIII & & & & & & & \\
\hline
\end{tabular}

FIGURE 10. Photographs of a labeled pottery sherd with its drawing, and the database of pottery artifacts with their descriptive details, from the Sotk 2 site (2011-2015). (Photo Archive of Ushkiani Research Project.)

Table 1. General Database Schema for Sotk 2 Artifacts, Sotk 2 Site, 2011-2015.

\begin{tabular}{|c|c|c|c|c|c|c|}
\hline \multicolumn{2}{|l|}{ Group } & Object Number & Passport Date & General Description & General Description Details & Classification Details \\
\hline Ceramic object & $\begin{array}{l}\text { Vessel } \\
\text { Others }\end{array}$ & & & $\begin{array}{l}\text { - preservation } \\
\text { - coordinate }\end{array}$ & $\begin{array}{l}\text { Further elaboration of specific } \\
\text { descriptive information }\end{array}$ & $\begin{array}{l}\text { Comments on object } \\
\text { types and chronologies }\end{array}$ \\
\hline Metal object & & & & - measurements & & \\
\hline Stone object & & & & - colors & & \\
\hline Obsidian object & & & & - description & & \\
\hline Bone object & & & & & & \\
\hline Others & & & & & & \\
\hline
\end{tabular}

attempts to organize and summarize these observations about scale and data collection methods. A particularly salient distinction exists between data concerning space and those associated with objects.

We also observe that we are already deploying several digital technologies regularly_drones, digital cameras, remote sensing imagery, total stations, GPS devices, GIS, 3D modeling, and Access databases. Our projects have a mix of new technology and traditional recording methods-with paper diaries, paper forms, and structured paper labels all central to our ability to collect and track information. Such a disparate set of tools and methods can become unwieldly at times, and it requires extra effort to make everything work together seamlessly. Simply keeping up with battery charging for all the devices is a challenge.

After we collect the data in the field, we bring everything into a lab environment, and we continue to work on the digital data. We need to keep track of digital image files of photographs or scans of handwritten documents, and we use some of these image files to create 3D models of sites and architecture through photogram- 


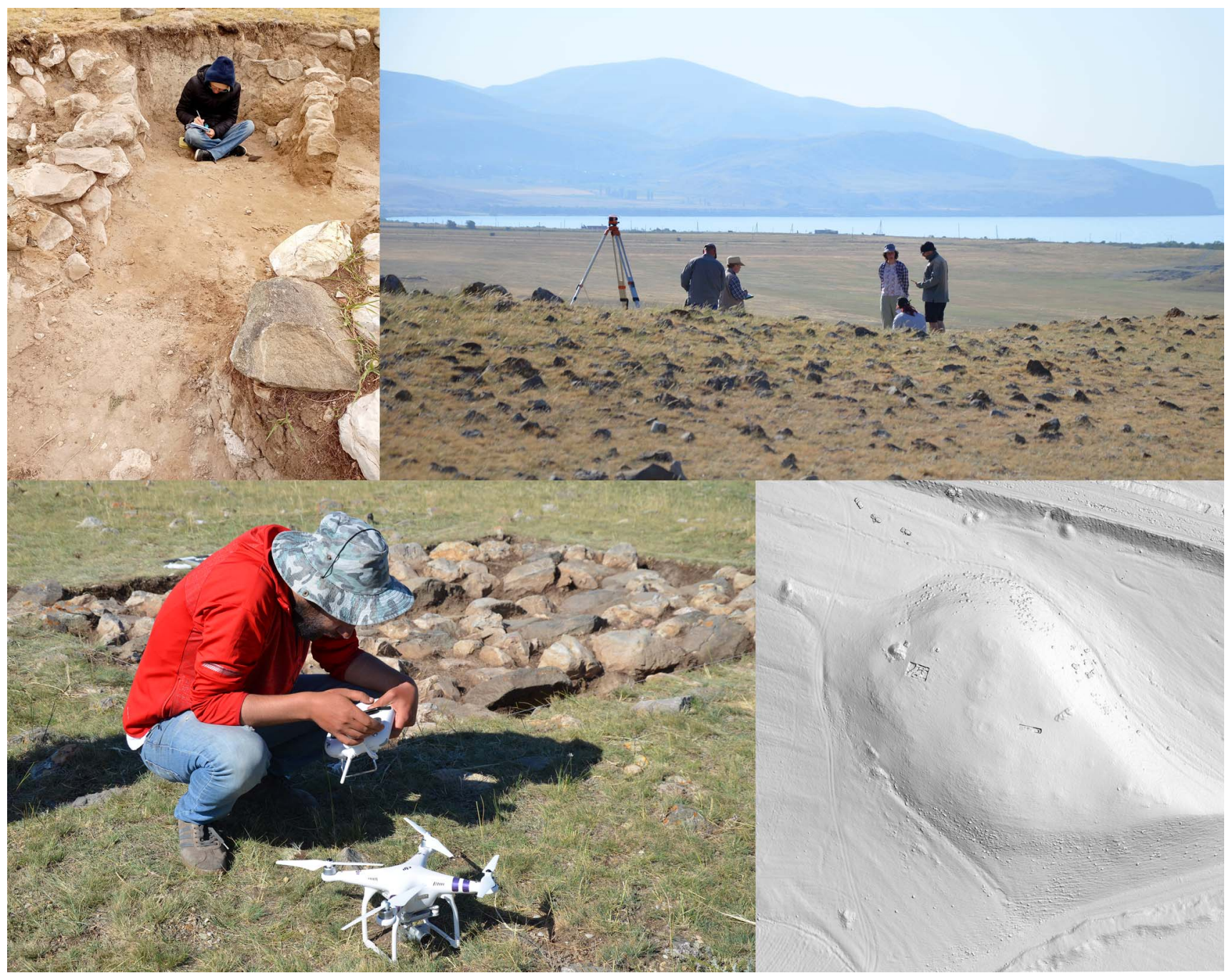

FIGURE 11. Field documentation practices at the Artanish 9 Trench A (2021), including drone orthophotography used to build the digital elevation model of the site, as shown at bottom right. (Photo Archive of Ushkiani Research Project.)

metry. We record spatial information from various sources into our GIS, and we record other information about artifacts and sites into our Access databases. Collecting all these data may eventually allow research advancements based on machine learning (Bickler 2021). It would also be possible to interact with our 3D models for research purposes using augmented or mixed reality (Liang 2021). Given the size of our team, the management of these data sometimes proves challenging, and we remain vigilant in training team members about how to integrate data into the system.

\section{FUTURE DIRECTIONS}

There are multiple challenges in contemporary archaeological fieldwork. Because sites are often very remote, the speed and quality of work are important factors for successful surveys and excavations. Archaeologists continuously face time and other resource limitations, so digital technologies offer the potential to improve efficiency.

We hope to have more portable equipment in the future-for example, to replace our use of the heavy total station for positioning. We also foresee a need for increased internet access in remote locations, which can help maintain connectivity for various pieces of digital equipment. Better internet would also enable us to directly upload data into databases from the field, thereby speeding up the recording process and centralizing data to enhance collaborative research. Perhaps in the near future, robots will be able to help transport heavy equipment or automate artifact processing (Wang et al. 2021).

For specific types of data, we could use technologies that make $3 \mathrm{D}$ modeling faster and easier, along with software that could record colors, shapes, and other characteristics of artifacts. Finally, we recognize that there are many diverse types of data 


\section{DIGITAL REVIEW}

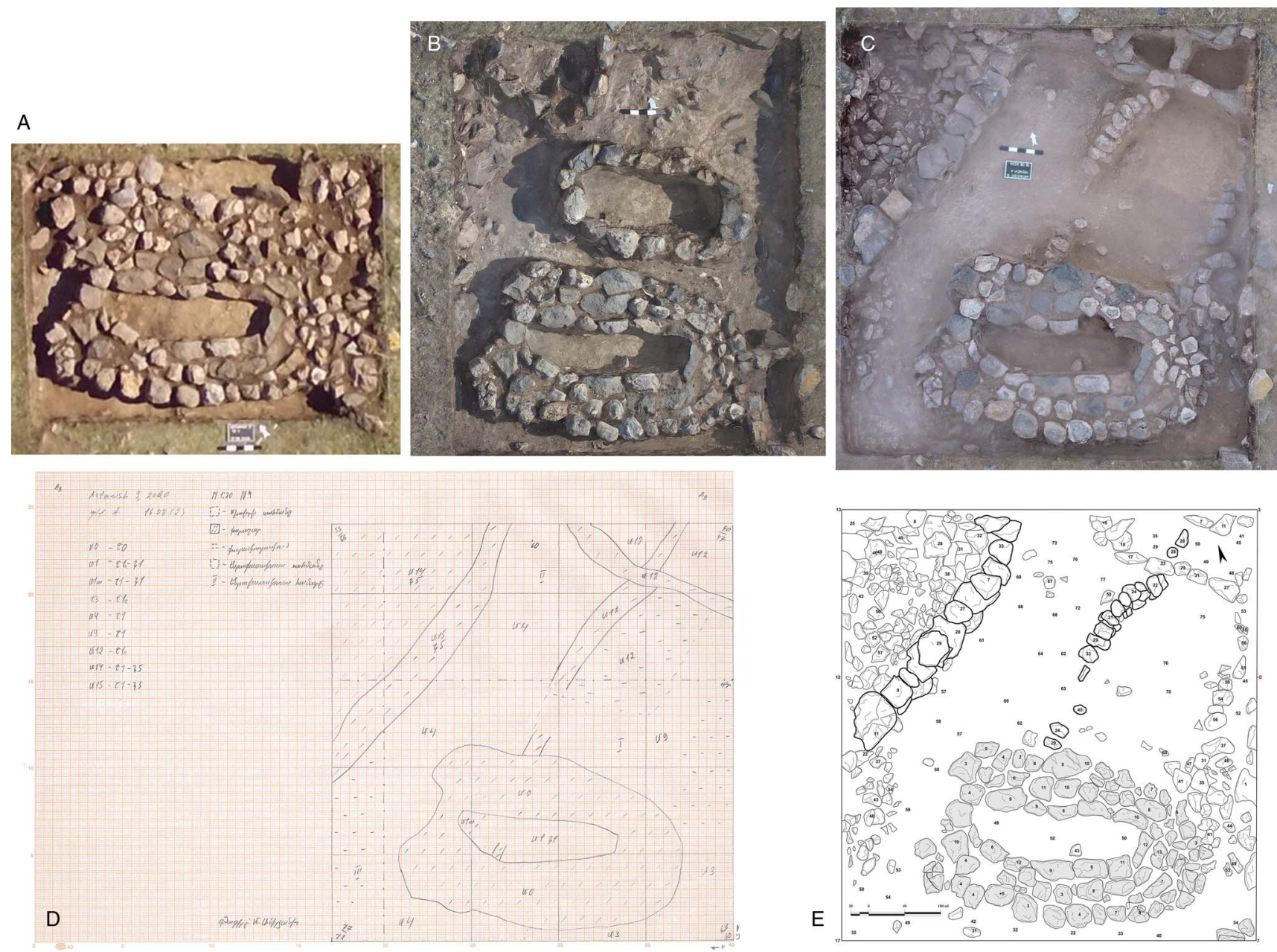

FIGURE 12. Drone photos of trench widening for Trench A from the Artanish 9 site (2020-2021): (A) $4 \times 3 \mathrm{~m}$, (B) $4 \times 5 \mathrm{~m}$, (C) $5 \times 5 \mathrm{~m}$; (D) a daily situational plan; and (E) the final drawing. (Photo Archive of Ushkiani Research Project.)

Table 2. A Visualization of the Relationship between Scales of Data Collection and the Manual and Digital Methods Currently Deployed for Each.

\begin{tabular}{|c|c|c|}
\hline Scale & Manual Methods & Digital Methods \\
\hline Landscape & Car Survey & $\begin{array}{l}\text { Remote Sensing (Satellite Imagery, Topographic Maps), } \\
\text { GIS }\end{array}$ \\
\hline Site & Intensive Walking Survey, Site Recording Form, Excavation Diary & $\begin{array}{l}\text { GPS Points, Drone Orthophotography and 3D Models, } \\
\text { GIS, Digital Photography }\end{array}$ \\
\hline $\begin{array}{l}\text { Features and } \\
\text { Contexts }\end{array}$ & $\begin{array}{l}\text { Excavation, Daily Drawn Plans, Excavation Diary, Stratigraphic } \\
\text { Recording Form, Conservation }\end{array}$ & $\begin{array}{l}\text { Geophysics, Drone Orthophotography and 3D Models, } \\
\text { Digital Photography, Digitized Plans }\end{array}$ \\
\hline Artifacts & $\begin{array}{l}\text { Excavation, Collection, Cleaning, Daily Drawn Plans, Object } \\
\text { Passport Label, Artifact Drawings, Conservation }\end{array}$ & $\begin{array}{l}\text { Total Station, Access Databases, Digitized Plans, Digital } \\
\text { Photography }\end{array}$ \\
\hline
\end{tabular}

being collected during a typical archaeological day. Currently, these are often collected with different equipment (including paper), and they consequently end up separated in the computer as distinct and disconnected files. We look forward to a time when the software will automatically connect them, analyze them, and generate statistics-while still enabling each project to work with its own data structures and recording system. 


\section{REFERENCES CITED}

Avetisyan, Pavel, and Arsen Bobokhyan

2012 Archaeology of Armenia in Regional Context: Achievements and Perspectives. In Archaeology of Armenia in Regional Context, edited by Pavel Avetisyan and Arsen Bobikhyan, pp. 7-16. Gitutyun, Yerevan, Armenia.

Bickler, Simon H.

2021 Machine Learning Arrives in Archaeology. Advances in Archaeological Practice 9:186-191. DOI:10.1017/aap.2021.6.

Casana, Jesse, Adam Wiewel, Autumn Cool, Austin C. Hill, Kevin D. Fisher, and Elise J. Laugier

2017 Archaeological Aerial Thermography in Theory and Practice. Advances in Archaeological Practice 5:310-327. DOI:10.1017/aap.2017.23.

Cobb, Peter J., Tiffany Earley-Spadoni, and Philip Dames

2019 Centimeter-Level Recording for All: Field Experimentation with

New, Affordable Geolocation Technology. Advances in Archaeological Practice 7:353-365. DOl:10.1017/aap.2019.21.

Kansa, Eric, and Sarah Whitcher Kansa

2021 Digital Data and Data Literacy in Archaeology Now and in the New Decade. Advances in Archaeological Practice 9:81-85. DOI:10.1017/aap. 2020.55 .

Liang, Jiafang

2021 Mixing Worlds: Current Trends in Integrating the Past and Present through Augmented and Mixed Reality. Advances in Archaeological Practice 9:250-256. DOI: 10.1017/aap.2021.16.
Lindsay, lan, and Ningning N. Kong

2020 Using the ArcGIS Collector Mobile App for Settlement Survey Data

Collection in Armenia. Advances in Archaeological Practice 8:322-336.

Lindsay, lan, and Adam T. Smith

2006 A History of Archaeological Practices in Armenia and the South

Caucasus. Journal of Field Archaeology 31:165-184.

Wang, Deborah, Brandon Lutz, Peter J. Cobb, and Philip Dames

2021 RASCAL: Robotic Arm for Sherds and Ceramics Automated Locomotion. In 2021 IEEE International Conference on Robotics and Automation (ICRA), pp. 6378-6384. IEEE, New York. DOI:10.1109/ICRA48506.2021.9561057.

\section{AUTHOR INFORMATION}

Artur Petrosyan, Hayk Azizbekyan (azizbekyan13@gmail.com, corresponding author), and Boris Gasparyan Institute of Archaeology and Ethnography NAS RA (National Academy of Sciences of the Republic of Armenia), Yerevan, Republic of Armenia

Roberto Dan —ISMEO - The International Association for Mediterranean and Oriental Studies, Rome, Italy

Arsen Bobokhyan and Mariam Amiryan $\square$ Institute of Archaeology and Ethnography NAS RA (National Academy of Sciences of the Republic of Armenia), Yerevan, Republic of Armenia 